\title{
CRISTÓVAM, MLENE E MINHAS MEIAS FURADAS... OU DE COMO UMA APRENDIZ DE PROFESSORA ENSINA POLÍTICA CULTURAL, SEM SABER, A UMA GRADUANDA DAS ARTES... OU AINDA... DOCÊNCIA: A BARCA DE CARONTE.
}

Maria ZéLIA Borba RochA*

Este texto não é acadêmico. Tampouco tem a pretensão de ser literário. É exatamente como se apresenta, nem mais, nem menos: esta coisa híbrida, sem forma, diria até sem identidade: pretendendo conter em si um pouco de cada, acaba por não ser nenhum dos dois. Mas há uma certeza: é um texto transgressor. Transgressor do rigor científico, transgressor da pureza literária. Não posso, entretanto, negar sua existência. Foi assim que emergiu à luz, e é assim que se faz conhecer ao mundo.

RESUMO: Este artigo trata da relação professor-aluno em um contexto democrático. É fruto de uma experiência docente e ressalta a dimensão humano-afetiva no processo educacional sem, contudo, esquecer-se dos aspectos científicos. Pelo contrário, enfatiza a importância do conhecimento científico como fundador/consolidador de vínculos societais. Objetiva demonstrar a relação existente entre conflito-prazer-paixão-responsabilidade inerente ao fazer educativo.

Palavras-chave: docência; conhecimento científico; relação conflito-prazer-paixão-responsabilidade; consciência político-social; democracia.

Era estudante ainda, menina de tudo, deslumbrada com a Universidade e com a vida, feliz por ter cortado o cordão umbilical com a casa paterna/materna, inebriada com o ar da liberdade dos vinte anos, quando ia ouvir Cristóvam Buarque nos anfiteatros da UnB. Sua fala fácil,

\footnotetext{
* Historiadora, mestre em Sociologia, professora da Faculdade de Educação da Universidade de Brasília (UnB). E-mail: zelia @unb.br
} 
cristalina e empolgante seduzia. Falava de democracia e de exclusão. Da condição essencial da transparência em uma sociedade/Estado/governo democráticos. Da necessidade imprescindível de superar a exclusão social em todas as suas formas: econômica, política, educacional e cultural, para construirmos uma sociedade efetivamente democrática. Da parte que cabia a cada um de nós, em especial às futuras gerações, todos de alguma forma educadores nas mais diversas profissões, na concretização do sonho de uma sociedade melhor para todos nós.

Mas a atitude que mais me impressionou em Cristóvam foi quando o embaixador do Chile foi fazer uma palestra sobre Pablo Neruda no anfi nove. Nós, os estudantes presentes, e não éramos poucos - todo o anfi, inclusive as escadas laterais, e a entrada no corredor estavam tomadas - literalmente, não permitimos. Aos berros, cantorias, batuques zorra total - alegávamos que o embaixador, alinhado com a ditadura chilena, não tinha moral para falar sobre Pablo Neruda. Era o ano de 1986, se não me engano. Cristóvam, tranqüilamente sentado ao meu lado (ou será que era eu que estava sentada ao lado dele?!), assistia a tudo - ele, sem consciência da existência de minha pessoa, é claro. Argüido pelos arautos do embaixador, respondeu que nada podia fazer: "A Universidade é deles. Eles é que mandam na Universidade. Sem eles, a Universidade não existe. Se os estudantes não querem que o embaixador fale, eu nada posso fazer." Até hoje não sei se essa foi a decisão de um Reitor popular, de um democrata convicto, de um político carismático ou de um intelectual transparente.

Prá terminar a história, saímos e fechamos a porta, deixando o embaixador falar para o minúsculo séquito chileno que o acompanhava. Cristóvam, claro, saiu conosco, sendo ovacionado pelos estudantes no corredor do minhocão sul.

Éramos a geração oitenta. Uma geração perdida entre os ecos e o silêncio... Os ecos dos movimentos culturais, políticos e estudantis de 68 que, apesar de terem sido gritados dezoito anos antes, ainda ressoavam fortes n'alma de todos nós, por meio de nossos referenciais: as músicas de Chico, Caetano, Gil; os filmes de Glauber, Hector Babenco e Cacá Diegues; os livros clandestinos da década anterior que agora circulavam livremente entre nós; as leituras densas de Raymundo Faoro, Celso Furtado, Caio Prado Júnior, Florestan Fernandes e tantos outros que, efetivamente, estudávamos na graduação e que, impressionantemente, conseguíamos relacionar à nossa realidade. E o silêncio dos anos setenta, que tocava alto em nossos peitos, com todos os mortos e desaparecidos... as listas eram então públicas. 
Mas também com a esperança e a consciência do trabalho de democratização por realizar. Nossos mestres (ídolos ou mitos?!) conduziam nossos passos: o movimento pelas Diretas-Já reuniu todos nós, independente das várias bandeiras partidárias, nos gramados do Congresso (à época, sem o espelho d'água que ACM mandou fazer) ${ }^{1}$ até as cinco da manhã, quando saímos então tristes e cabisbaixos, abraçados uns aos outros e subimos à pé, por trás da esplanada dos ministérios, obrigados que fomos pelo exército presente, aquela fila enorme, no maior silêncio, até a rodoviária, para de lá, cada um tomar seu destino... A Constituinte de 1988 foi também prenhe de todos nós por meio de milhares de assinaturas nos abaixo-assinados que circulavam pela Universidade, reivindicando temas que não foram objetos de deliberação, como a descriminalização da prostituição e a legalização do aborto, mas também de outros que foram contemplados no texto constitucional. Assim como preenchemos as galerias do Congresso Nacional nos momentos cruciais de votação dos temas polêmicos e no emocionante cinco de outubro...

Os gramados do Congresso receberam-nos de novo, nos vários showmícios das eleições presidenciais de 1989, após 29 anos sem eleições diretas para presidente - era o acontecimento. E ainda estávamos presentes, agora como estudantes de pós e/ou profissionais, no mesmo gramado, ainda sem o espelho, quando do impeachment de 1992. Embora há muito não fôssemos mais teenagers de cara pintada - a maioria casada e com filhos, muitos inclusive já divorciados - estávamos duplamente felizes, lavando a alma pela derrota de 1989, quando a depressão dos 15 dias deixou toda a nossa geração de cama, os olhos vermeIhos e inchados de tanto chorar - isso, colocando os militantes, os apaixonados e os simpatizantes todos no mesmo saco. À época, só aos poucos fomos, muito devagarinho, saindo do útero-lar e nos encontrando nos points usuais: Beirute, Cultura Inglesa, Cine Brasília, a própria Universidade. O processo de ressocialização demorou meses. Entretanto, em 1992, mais maduros, percebemos o grande ganho político-social da derrota de 89 e do impedimento: o Brasil superou a crise sem cair em antigas fórmulas autoritárias como golpes de Estado; o Legislativo, com todos os seus equívocos e vacilos, conseguiu trazer à tona e tornar transparente à Nação a ponta de um iceberg de atitudes patrimonialistas que lesavam todos nós; o aumento da consciência político-social daqueles que, em 89, foram indecisos. A derrota de 89 e o impeachment de 92 foram, inequivocamente, apesar das dores, ganhos democráticos.

Nesse ínterim, entre 1988 e 1999, freqüentamos também a comissão de educação e o plenário da Câmara dos Deputados de algazarra, nos 
momentos decisivos de votação da LDB. Nesse período, acontecimentos políticos importantes, como o badernaço contra o governo Sarney, a marcha do MST e a várias manifestações reivindicatórios de aumentos salariais levaram-nos de volta ao gramado da esplanada dos ministérios. Estávamos lá também quando foi preciso lutar pela reivindicação da Câmara Distrital em Brasília, nós, os filhos adotivos e os naturais desta Cidademenina que, apesar dos quarenta anos, ainda é uma adolescente.

Esse foi o trilhar, em rápidas palavras (não está tudo aí), de uma estudante que hoje se aprende professora...

Já professora, Milene chegou para mim como todos os alunos chegam no início do semestre: um pouco esperançosos que algo de novo aconteça no cotidiano de suas disciplinas; um pouco desencantados com a Universidade; confusos nestes anos noventa, perdidos entre globalização, neoliberalismo, reforma do Estado, terceira revolução tecnológica, exclusão social... em média, parecem-me mais confusos e perdidos que minha geração. E o que é pior... desesperançados, ou com uma esperança sem lucidez, sem um norte a seguir, a não ser o individual... sem referenciais... ou com "Mamonas Assassinas", "Tiririca", "É o Tchan", e os milhares de grupos de pagode e happy, dos quais não consigo distinguir nenhum, como referenciais! Não só. Também cheios de energia, dominando a multimídia como nós não dominamos, com um volume de informações, uma rapidez de raciocínio, uma vontade de aprender e de fazer algo fora do comum, impressionantes. Enfim, como todos nós aos vinte anos, em busca de um significado para a existência, descobrindo o mundo, achando que estamos "inventando a roda", mas com um combustível de vontade para realizar algo concreto, de forma individual e coletiva.

Os olhinhos inquietos e o sorriso luminoso de Milene chamaram-me a atenção logo no primeiro dia; como num rasgão, num flash, emergiu, do fundo do baú, uma frase de Paulo Freire que ficou de uma das muitas disciplinas que fiz e da quantidade quase infinita de textos de xerox que li, como aluna mesmo: "Para ser educador é necessário amar profundamente. Amar profundamente as pessoas e o conhecimento...". E cursamos um semestre conturbado, com uma greve docente de três meses no meio do caminho. Mas era uma turma especial, não se dispersou (mas não furamos greve! Enquanto rolava a greve, preparavam os seminários que, orientados anteriormente, ao serem apresentados depois, mostraram a paixão e o interesse da "galera" e de como, inequivocamente, o conhecimento serve de amálgama entre vínculos). Estudamos tanto que ultrapassamos o número de horas/aula da disciplina (dez a mais) e eles nem perceberam... 
Turma mais heterogênea, impossível: físicos, matemáticos, futuros professores de português, de inglês, de educação física, historiadores, geógrafos e duas pedagogas (a monitora e uma "apêndice", que não se definia em ser aluna-ouvinte, turista ou co-monitora) e, é claro, os artistas: músicos e bailarinos. Total: cinqüenta e cinco pessoas, incluindo aqui a pretensa socióloga no meio deles. Ao final do semestre, tivemos direito a churrasco com fotos e tudo, que a Karine organizou na casa do Pedro.

A singularidade da turma não significa a simplificação de que o processo foi isento de conflitos, mas a abertura suficiente para compreender que não só um ensina, mas que todos educam a todos. ${ }^{2} \mathrm{E}$ que $\mathrm{o}$ conflito é mestre, quando se dispõe ao desprendimento das verdades empedernidas, fossilizadas, e se deixa deleitar pelo fascínio que a exploração de novos universos proporciona. Mas não se deixem conduzir pela lógica formal simplista que possibilita o raciocínio dedutivo que o proceder educacional foi esvaziado de conteúdo - no sentido do conhecimento científico. Pelo contrário, foi um semestre hard de leituras e trabalhos acadêmicos, quando estudamos, minuciosamente, a reforma do Estado, as relações dessa conjuntura com as mudanças no sistema educacional brasileiro, os críticos da reforma e, finalmente, o que cabe a nós, todos professores - atuais e futuros - fazer como sujeitos políticos, na construção cotidiana de um novo projeto de vida, agora que as ideologias tradicionais, que serviram de norte às gerações anteriores, encontram-se esvaziadas de sua força condutora de multidões. ${ }^{3}$

A turma de estrufunc ${ }^{4}$ 1\%/98 continuou encontrando-se mesmo depois de findo o semestre letivo, durante os três próximos semestres, em um amigo "oculto-claro" na casa da Karine, em um lual na casa do Léo e em uma noite de queijos e vinhos lá em casa. Isso porque doía, em todos nós, a perspectiva de desfazer o vínculo constituído durante o longo semestre letivo, com a intensidade das três vezes por semana. Frutificou uma amizade sólida entre um físico e um desportista (Gustavo e Léo); um namoro entre dois desportistas (Karine e Pedro); um poema romântico que o doce e meigo Renato, aluno da Educação Física, legou-nos naquele semestre, motivado pelos laços que a convivência criou em todos nós e pelos conhecimentos que ensinamos uns aos outros; ${ }^{5}$ a aprovação na seleção do Mestrado da pedagoga apêndice-turista da turma - Adriana; um projeto de pesquisa, iniciação científica, para minha monitora - Patrícia; um projeto de diplomação entre uma artista e uma aprendiz de professora/socióloga: Milene e eu; e aqueles olhares e sorrisos gostosos de aconchego em cada um de nós, quando nos encontramos nos corredores da Universidade e da Cidade, resultado de uma mútua descoberta que só o exercício apai- 
xonado e rigoroso (no sentido filosófico) da docência propicia. Demoramos, neste caso, a assimilar a lição de que o mestre e os alunos devem aceitar a morte simbólica um do outro como parte inerente da jornada de conhecimento que percorreram juntos.

Fevereiro de 1999. Estamos no segundo semestre letivo de 1998. Saio da aula de minha nova turma, quando vejo aquele andar de dançarina no corredor. Milene queria ajuda para seu projeto de diplomação. Como estudou política educacional comigo, achou que eu poderia ensinar política cultural. $\mathrm{Na}$ atitude tipicamente ingênua da ainda adolescente (apesar da idade) meio delinqüente academicamente, vislumbrei a possibilidade de abrir novos horizontes, de adentrar universos nunca dantes explorados por mim, de aprender coisas novas e, irresponsavelmente, topei. Formalizada a orientação diante do Departamento de Artes Cênicas e do de Planejamento e Administração, começamos a estudar. Duas noites por semana foi o horário possível de conciliar, e ficávamos das oito as quase onze, apenas com o lanchinho magro do quiosque, no frio da minha sala de trabalho, na solidão da Faculdade de Educação, quando constatava, ao final de cada jornada diária de trabalho, que minhas meias finas furavam, invariavelmente, no dedão do pé esquerdo.

Mas nunca estávamos sós. Figuras ilustres compareciam às nossas incipientes e simplórias discussões: Gramsci, Cristóvam Buarque, Alfredo Bosi, João Francisco Duarte Júnior, Marilena Chauí e, por intermédio deles, o velho Marx, que não morreu como dizem por aí, e até, pasmem, Weber e Habermas concediam-nos a honra de sua presença. Procurávamos o túnel de entrada teórico para desenvolver a relação arte-educação na política cultural implementada pelo Governo Cristóvam Buarque no Distrito Federal de 1994 a 1998. Hoje percebo que havia outros vultos ali. Silenciosos, nada falaram até que todos se fossem, inclusive Milene. Não que eu disponha de qualquer tipo de deferência especial da parte deles... mas como falavam tão baixinho, foi preciso que os demais saíssem para que eu, na minha condição de neófita, conseguisse ouvi-los.

No percurso, tornamo-nos amigas. O estudo dos documentos do Governo, dos textos teóricos, a seleção do material pictográfico, o planejamento da exposição oral e artística, e a correção da monografia começaram, timidamente, a ser permeados de confidências, desabafos, risos... indisciplina... discutíamos os conceitos de cultura, arte, educação e falávamos das decepções e expectativas amorosas; procurávamos a relação teórica entre passado, presente e futuro na construção da identidade cultural em Brasília e contávamo-nos as angústias existenciais; desenvolvíamos os nexos entre 
cultura, arte e democracia e desabafávamos os pesos do dia-a-dia; aborrecíamo-nos com as dificuldades burocráticas para conseguir os documentos e confidenciávamo-nos as preferências sexuais; divertíamo-nos com as fotos, folders, cartazes e entristecíamo-nos com a dureza da realidade quadruplamente excludente: financeira, política, educacional e artística. Entre dúvidas de português, vacilos teóricos e descobertas novas - de como, por exemplo, os princípios da razão comunicativa de Habermas aplicam-se a quaisquer tipos de relações entre pessoas, tanto no espaço público quanto no privado, inclusive e, principalmente, às amorosas ${ }^{6}$ - foi fácil constatar como duas gerações diferentes de mulheres são tão iguais e, por intermédio de nossas trocas de experiências, impressões e "conselhos" mútuos, como gerações masculinas são também tão parecidas, tão deliciosas e, ao mesmo tempo, tão dolorosamente necessárias.

Quando todos se foram, os vultos silenciosos sussurraram-me, nas madrugadas insones, a história de Caronte, o barqueiro dos deuses do Olímpo, cuja função era conduzir as almas humanas em sua jornada ao reino de Hades. Hades era um reino complexo, composto de três dimensões: "O terceiro e último ato do drama gigantesco da existência e da morte é precisamente a sorte que aguardava a alma no além e o caminho perigoso que a conduzia até lá e a trazia de volta ao mundo dos vivos, para recomeçar uma nova tragédia". ${ }^{7}$ Para se chegar até ele, ou para se sair dele, necessitava-se enfrentar Cérbero, o guardião do reino, monstro de três cabeças, cauda de dragão e corpo de serpente, assim como atravessar os quatros rios: o das chamas ardentes, o de águas gélidas, o rio das águas paradas e o rio dos lamentos. Essa era a ciência de Caronte, o único capaz de domesticar Cérbero e o único que conhecia os caminhos através dos quatro rios e de como superar os perigos próprios a cada um deles. Enfim, o único que conhecia o caminho de entrada e de saída do reino de Hades.

Se associada a uma moral cristã, o reino de Hades passou a significar o inferno que espera todos nós além dessa existência terrena, laicizada, essa simbologia oferece-nos uma riqueza e uma complexidade de interpretação muito mais abrangentes. Ressignificada, a passagem obrigatória por Hades simboliza a trajetória humana na construção de sua consciência, de sua identidade, de sua personalidade e de sua individualidade. Construção que é autoconstrução, mas que também é construção partilhada por aqueles que nos acompanham nesse barco. Trajetória na qual temos, quer queiramos, quer não, de atravessar certos percalços, de superar certos estágios. Cada um deles requer uma metodologia diferente, assim como para atravessar quatro rios de águas tão diversas, Caronte necessitava adotar procederes múltiplos, na condução do barco. 
Assim, sussurram-me os vultos silenciosos, que somos todos, no exercício da docência, barqueiros Caronte. Recebemos, a cada semestre, essas almas: ${ }^{8}$ algumas ávidas, outras indiferentes; algumas iradas, muitas perdidas... os rostos jovens, os olhares ansiosos, os sorrisos incertos, inseguros traduzem desejos, esperas, anseios... alguns, fascinação; outros, apatia; há também os descrentes... mas enfim, almas que conduzimos nessa travessia e sobre cujo destino não temos qualquer poder, nenhum tipo de controle, ${ }^{9}$ apenas o prazer da companhia e o partilhar da paixão pelo conhecimento. Senhores de seus próprios destinos, escolhem sua rota e eles mesmos remam o barco, assim como Caronte não remava o barco, eram as almas que o faziam, ele apenas o conduzia. Nós, carontes, não passamos de guias, por já termos navegado nessas águas, que contribuem mostrando como se supera os perigos inerentes a cada rio e, ao mesmo tempo, como se aprecia a paisagem (o conhecimento), chamando atenção para um detalhe ou outro.

Mas nossos navegantes são atentos: alguns à paisagem, uns aos colegas de travessia; há ainda os que nada lhes chamam atenção, e há também os que observam o condutor do barco - um gesto, uma fala, um olhar -, nada lhes escapa... e, então, sem que saibamos, sem que percebamos, tornamo-nos modelos, referencial de profissional, de pessoa, de homem, de mulher. Modelo negativo como fui há alguns semestres: "professora, com a senhora aprendi o tipo de professor que eu não desejo ser", ou referencial positivo de que servi, em outro semestre: "professora, "quando crescer', quero ser igual à senhora". Deixei de angustiar-me. Entendi que perfeição não existe. Até porque o olhar de quem observa é guiado por referenciais muito próprios, que escapam ao objeto olhado. Perfeição é uma possibilidade a ser constantemente construída/reconstruída nessa relação, onde se percebe a sedução de um sobre o outro. Há um diálogo mudo e mútuo, subterrâneo, de ambas as partes. Carregado de olhares, gestos e sorrisos que traduzem sensações silenciosas e contrastantes. Uma relação mútua de sedução que não pode prescindir do abandono de nossos narcisismos e onipotências, se quisermos imprimir a qualidade que vai plasmar a possibilidade do extraordinário no corriqueiro. ${ }^{10}$

Dessa responsabilidade não há como escapar. Mas sem que esse peso signifique deixar-nos sem fôlego, sem ação, paralisados. Pelo contrário, com a consciência que fornece os instrumentais cognitivos, éticos, morais e emocionais necessários à formação profissional e, portanto, de inserção no mundo do trabalho e, por conseqüência, na esfera social; que vão possibilitar condições para a construção da consciência coletiva, permitindo ao indivíduo, pelo acesso às diversas áreas do saber, si- 
tuar-se conscientemente no mundo em que vive e, portanto, de fazer opções lúcidas e refletidas - racional e emocionalmente (guardadas as devidas proporções); que o processo educativo constitui um espaço privilegiado de formação de vínculos societais e afetivos. Com a leveza de espírito, tanto quanto seja possível, para vislumbrar - criar, aos poucos - a luz de saída do peso de nossa realidade cotidiana e torná-la plena de prazer e de significado, de paixão pelo aqui e agora.

Como realizar cada viagem, que é sempre a mesma, de forma diferente? Como não nos queimarmos nas águas quentes do rio da revolta, às vezes muda, às vezes declarada, que o peso do cotidiano pode despertar em nós? Como não nos congelarmos nas águas gélidas do rio da indiferença, a que a repetição rotineira pode nos conduzir? Como não nos deixarmos sufocar pelas águas paradas e lodaçais do rio da apatia e do desânimo, a que as pedras do dia-a-dia podem se transmudar? Como não nos ensurdecermos pelas águas barulhentas e estéreis do rio do queixume, a que a reprodução interminável da mesmice pode nos levar? Só com a pulsão da paixão. Para fazer a mesma viagem, infinitas vezes, o barqueiro necessita apaixonar-se pelas almas que estão, temporariamente, sob sua tutela; os carontes precisam criar o prazer pela própria atividade de conduzir almas através de uma difícil jornada; docentes não podem prescindir da busca incessante e amorosa pelo conhecimento e se convencerem "de que é preciso empregar tudo a fundo, inclusive a própria pessoa". ${ }^{11}$ Se assim não for, nosso trabalho corre o risco de transformar-se em trabalho de Sísifo, cuja tarefa diária consistia em mover uma pedra montanha acima, por castigo que Zeus Ihe impôs pela eternidade, para ver, desconsolado, ao final de cada jornada, a mesma pedra rolar montanha abaixo. O trabalho de Sísifo simboliza, assim, o trabalho estéril que não transforma realidade, não nos modifica e não contribui para construir o outro, como ainda constitui um peso a quem o desenvolve.

Enfim, fazer junto essa viagem, nascer de novo a cada semestre, a cada nova turma, transformando a simbologia do ato de conhecer - cum + gnosco = captação conjunta, com-preensão “... permite relacionar com nascimento"12 - em atitude cotidiana e descobrir que docência é paixão. E paixão é compromisso. E compromisso não é peso, mas prazer, emoção compartilhada com a busca da competência coletiva. E ninguém mais compromissado que o Ser apaixonado. Atento, cuidadoso, zeloso quanto às necessidades do outro: "Para criar um compromisso e desenvolver uma história compartilhada, uma pessoa deve dar-se à outra." ${ }^{13}$ A referência de mundo, de vida, para o Ser apaixonado é o outro, no sentido do vínculo que se constitui entre os universos envolvidos. E o vínculo passa a 
ser o Novo Ser, o eixo em torno do qual giram os referenciais anteriores que, dissolvidos em uma nova unidade, transmudaram-se em outra natureza. Mas para que isso aconteça, é necessário ter a flexibilidade suficiente de abstermo-nos de nossas pré-noções, ${ }^{14}$ o que nem sempre é fácil, nem sempre é prazeroso. Pelo contrário, via de regra é doloroso, quando não é traumático. Implica arrancar a pele que nos protege, servindo de filtro pelo qual passam as experiências vividas e, ao mesmo tempo, possibilita o prazer das coisas vivenciadas. Abstermo-nos de nossas pré-noções significa virar o mundo de cabeça prá baixo, promovendo a revolução do cotidiano, sem esquecermo-nos de que a síntese - o novo, o inédito advém do amálgama dos elementos constituintes anteriores. ${ }^{15}$

A defesa de uma lógica pautada na irracionalidade do instinto passional pode parecer paradoxal em uma atividade que se desenvolve no espaço da racionalidade por excelência no mundo moderno - a Universidade. ${ }^{16}$ Entretanto, a paixão oferece a possibilidade de revolucionar a ordem estrutural cotidiana e conferir um outro significado à atividade, bem como às pessoas envolvidas. Se, como afirma o senso-comum, deixa-nos cegos a realidade porque oblitera a razão, por outro lado, "nasce como projeto de reconstituir concretamente o existente, de organizar (...) a vida presente, passada e futura, e de fazê-lo de maneira exemplar (...) é um projeto de transformação concreta e por isso uma perspectiva desse gênero parece a muitas pessoas um fracasso". ${ }^{17}$ Se, minimamente, a docência puder transmitir essa luminosidade a nossos fugazes instantes de sala-de-aula, estaremos acrescentando um ingrediente novo, não só à atividade em si, como às subjetividades envolvidas ${ }^{18}$ no processo e mesmo aos resultados da jornada, ainda que desses, na maioria das vezes, não consigamos tomar ciência de imediato. E, ao meu ver, esse ingrediente é tão mais indispensável quando se trata de formar educadores que, de uma forma ou outra, no exercício das mais diversas profissões (as palavras de Cristóvam, no início do texto...) serão também educadores. A Universidade, assim, no que tange à sua função formadora, tem dupla responsabilidade, porque forma formadores que vão dar prosseguimento aos "elos da corrente", formando novas mentalidades, em outros níveis, e podem fazer isso de maneira singular, extraordinária, ou apenas reprodutivamente.

$\mathrm{E}$ o que nos cabe fazer, agora que as luzes das macroideologias, que conduziram a ação das gerações passadas, estão apagando-se e não conseguem mais apaixonar multidões, em especial às novas gerações? Talvez deixarmos de viver em abstrato ${ }^{19}$ e voltarmos nossos olhos para os lados - para o semelhante - e perceber a profundidade e a amplitude do dia-a-dia. Construir o prazer e a paixão no cotidiano de nossas atividades 
rotineiras, conferindo-lhe a plenitude de significados imprescindíveis ao viver "sabendo utilizar os sentidos do máximo de suas potencialidades, acede-se a uma vida social que não é nem abstrata, nem desencarnada, mas que repousa, ao contrário, sobre a (...) valorização do que faz a natureza humana." ${ }^{20}$ Isso é ser radical - no sentido etimológico, daquele que mergulha em profundidade, que vai à raiz para buscar o que é essencial, básico, fundamental e, assim, viver a plenitude e a profundidade das relações humanas. Com a responsabilidade de quem sabe que a felicidade não se encontra em nenhuma estação aonde vamos chegar - como nos fizeram acreditar as ideologias prospectivas ${ }^{21}$-, mas que é possível de ser construída, cotidianamente, pela ação concreta, do dia-a-dia, de forma individual e coletiva. Sem essa perspectiva, o peso da concretude diária nos abafa, a rotina do fazer obrigatório nos oprime e o cotidiano tira o encanto - de tudo, de todos - porque o peso do dia-a-dia transforma o mais singular, o mais inédito em comum, em banal, por meio da proximidade, da continuidade e da repetição.

$\mathrm{E}$ a relação de tudo isso com minhas meias finas furadas ao final de cada jornada diária de trabalho? Também não sei. Só sei que educar para a democracia é educar para a transgressão utópica. Utopia aqui não no sentido do irrealizável, do inatingível, mas do possível de ser realizado através da ação política por excelência. E sala de aula é trabalho político por excelência. É político porque imprimimos nessas almas jovens, sedentas de saber e de viver, marcas. Marcas momentâneas, algumas indeléveis. Marcas obscuras, outras luminosas. Mas, enfim, plasmamos realidades quando transformamos sede de saber, ou mesmo apatia, desânimo, descrença em conhecimento e ação ou, pelo menos, em desejo de conhecer e de agir

É trabalho político que se assemelha ao do beija-flor, que carregava pingos d'água em seu bico para apagar o incêndio da floresta. Assemelha-se porque, de imediato, é invisível. E é invisível porque não percebemos que, juntamente ao conhecimento, a relação interpessoal em sala de aula imprime em nossos espíritos as marcas da paixão ou da apatia, da mudança ou da mesmice, do compromisso ou da descrença: "O conhecimento dos alunos, suas opiniões, as opiniões do professor, tudo isso sofre transformações de todos os tipos, incontroláveis e, na maior parte das vezes, imperceptíveis". ${ }^{22}$ Sem dúvida que as gotas de conhecimento, de paixão, de competência e de compromisso (ou os contrários...) que possamos distribuir no exercício da docência não apagarão o incêndio em nossas almas, na Universidade e na sociedade, mas à semelhança do beija-flor, podemos responder, quando questionados pelos outros animais que fugiam do fogo e argumentavam que tal atitude não apagaria o incên- 
dio: "Eu faço a minha parte". É o contrário da atitude estéril dos Cínicos gregos, existentes até hoje, que questionam pelo questionar, implantam a descrença, a desesperança estéril que paralisa, e não abrem brecha de luz que permita vislumbrar uma alternativa de saída, ao nível macro, do coletivo, como ao nível micro, das relações interpessoais.

Só sei que educar para a democracia é co-educar-se para a transgressão da realidade que, constantemente, supera nossa imaginação e, por isso mesmo, requer maior empenho e mais criatividade. E, ao mesmo tempo, como Oscar Wilde sussurrou-me, na solidão das madrugadas sem dormir, que "somos responsáveis por tudo o que fazemos, por tudo o que deixamos de fazer e por tudo o que consentimos", ${ }^{23}$ em especial no que se refere à relação com o outro...

Recebido para publicação em 4 de outubro de 2000.

\section{Notas}

1. O espelho d'água consistiu em um mecanismo sofisticado de impedir as manifestações populares em um espaço de Brasília, tradicionalmente utilizado para a expressão pública e política das massas. Ou seja, Antônio Carlos Magalhães utilizou-se da estética na arquitetura para impedir "que a praça seja do povo".

2. A matriz desse pensamento é, reconhecidamente, Paulo Freire.

3. HOBSBAWM, E. A crise atual das ideologias. In: SADER, E. (org.). O mundo depois da queda. São Paulo: Paz e Terra, 1995, p. 213-26.

4. Estrutura e Funcionamento do Ensino de $1^{\circ}$ e $2^{\circ}$ graus I, a disciplina mais odiada das licenciaturas, inclusive por mim, quando estava na graduação... há um booooom tempo atrás...

5. Sistema:/Anda meio mal, ultrapassado/O coração está estático/Anda meio sufocado.//Não sei se a patologia está no coração/Ou se está no Sistema como todo/Sei que o Sistema vive do coração.//Há uma dúvida!/Devemos mudar o Sistema?/Ou tocar o coração?//Mais uma vez não sei/Só sei que cada um de nós/Deve ouvir seu próprio coração.

6. " $\left.{ }^{\circ}{ }^{\circ}\right)$ a disposição verdadeira dos interlocutores de não mentir e sempre dizer a verdade; $2^{\circ}$ ) a disposição sincera dos interlocultores de ouvirem-se uns aos outros, sem usar a violência; $3^{\circ}$ ) a disposição sincera dos interlocutores de serem imparciais, aceitando mudar de opinião e de posição quando reconhecem que a opinião ou posição alheias são mais verdadeiras, mais corretas ou mais justas do que as suas". CHAUÍ, M. Ética e Universidade. 46 $6^{a}$ Reunião Anual da SBPC, Vitória (ES), 1994, p. 2. (Mimeo).

7. BRANDÃO, J. Dicionário mítico-etimológico da mitologia grega. Vol. I, Petrópolis: Vozes, 1991, p. 375. 
8. O termo alma não está sendo usado aqui na conotação metafísica, mas no sentido etimológico: anima, significando o princípio da vida, dotado de consciência, individualidade e personalidade: "As funções da consciência e do espírito, próprias da personalidade individual". TEIXEIRA, J. In: Logos: Enciclopédia Luso-Brasileira de Filosofia. Vol. 1, Lisboa/São Paulo: Editorial Verbo, 1989, p. 151-73.

9. Não se desconhece a noção foucaultiana de que o poder opera por meio das instituições e, nessas, através das pessoas. Tampouco se ignora as teorias clássicas que alertaram para a função reprodutivista da escola e do professorado. O que se coloca aqui é a posição político-ética de abrirmos mão desse poder, tanto quanto seja possível, na dimensão educativa.

10. Ver desenvolvimento dessa idéia em GAUTHIER, C. \& MARTINEAU, S. Imagens de sedução na Pedagogia: A sedução como estratégia profissional. Educação \& Sociedade, Campinas: Cedes, ano XX, n 66, abril 1999, p. 13-54.

11. BEAUVOIR, S. Memórias de uma moça bem-comportada. São Paulo: Círculo do Livro, 1958, p. 63.

12. SILVA, C. In: Logos: Enciclopédia Luso-Brasileira de Filosofia. Vol. 1, Lisboa/ São Paulo: Verbo, 1989, p. 104-112.

13. GIDDENS, A. A transformação da intimidade. São Paulo: Unesp, 1993, p. 152.

14. A fórmula, expressa em As regras do método sociológico de Émile Durkheim, foi aqui destituída de sua significação metodológica e aplicada ao contexto das relações humanas.

15. O pensamento, sabidamente de origem Marxista, foi também esvaziado da conotação filosófico-social que a dialética legou-nos e ressignificado para o cenário micro das relações inter-subjetivas.

16. A relação entre paixão e conhecimento científico, portanto entre razão e paixão, não é absolutamente nova. Pode ser encontrada em várias acepções teórico-metodológicas, com posições diferenciadas: desde o funcionalismo clássico durkeimiano, que nos aconselha a mantermos um afastamento, até o holismo de algumas correntes que advogam ser essa uma relação indissociável, passando pela sensata posição weberiana que nos alerta que a objetividade é desejável e deve ser buscada, mas que o conhecimento objetivo vem carregado da subjetividade do pesquisador. O que se faz aqui é atribuí-la à docência, revestindo-a com argumentos mais intimistas, uma vez que estamos no âmbito das relações inter-subjetivas.

17. ALBERONI, F. Enamoramento e amor. Rio de Janeiro: Rocco, 1988, p. 83.

18. Embora seja desnecessário, é bom lembrar que a carga emotiva que reveste estas idéias aplicadas à docência não chega ao nível pessoal do encontro amoroso entre dois indivíduos.

19. Viver em abstrato significa, aqui, banalizar as atividades corriqueiras, destituindo o presente de sua fecundidade para emprenhar o futuro, a partir das ações cotidianas. 
20. MAFFESOLI, M. No fundo das aparências. Petrópolis: Vozes, 1996, p. 85.

21. Não se trata de negar a importância das ideologias fundantes do mundo moderno (ainda que em oposição entre si) e de propor uma substituição simplista por um presenteísmo hedonista que vive a soberania dos prazeres momentâneos e fugazes, sem projeto. Talvez se possa falar de uma aproximação a um epicurismo que vivencia o prazer na prática da virtude e no cultivo do espírito, cotidianamente. Nessa proposta, subjaz o projeto de construção de um mundo social e de seres humanos melhores, o que, em última instância, é também a proposta final das ideologias nascedouras na e da modernidade.

22. PIRSING, R.M. Zen e a arte da manutenção de motocicletas: Uma investigação sobre valores. São Paulo: Paz e Terra, 1988, p. 191.

23. Essa síntese pode ser abstraída de seu romance $O$ retrato de Dorian Gray.

\section{Cristóvam, Milene AND MY hole SOCKS... OR... How A NOVICE OF PROFESSOR TEACHES CULTURAL POLITIC TO A ART'S STUDENT... OR STILL... Teaching: fatboat's CARONTE.}

ABSTRACT: This article concerns about the relationship between professor and students in a democratic context. It results of the academician experience and to stand out the human-affective in the educational process. It emphasis of the cientific knowledg's importance how originator/consolidator of the sociais entails. It intends to demonstrate the relation between conflict-pleasurepassion-responsibility in the educational process.

Key words: teaching; scientific knowledge; political and social conscience; relation between conflict-pleasure-passion-responsability; democracy. 